\title{
Switching Power Supply Topology Structure Type and Structure Analysis
}

\author{
Ning Wang 1, a \\ 1 Xijing University, \\ Shaanxi Xi'an ,China \\ a E-mail: 2571449451@qq.com \\ Xiaoping Yang 3, c \\ 3Shaanxi step industrial co., LTD, \\ Shaanxi Xi'an ,China \\ cE-mail: 41564103@qq.com
}

\begin{abstract}
Switching power supply is a kind of low voltage and heavy current combination of complex power electronic device, switching power supply with the traditional test method research. This paper first introduces the development history of switch power supply, the emphasis on the switching power supply topology structure 、 the classification、 analysis and argument.
\end{abstract}

Keywords-switching power; topology structure; classification; analysis

\section{INTRODUCTION}

In the process of the development of the power switch converter, in the 1950s, pulse width modulation hard switching technology is unveiled a new beginning for the development of power electronic technology. PWM technology with its circuit is simple, convenient control and won a wide application. Generally speaking, PWM refers to maintain a constant switching frequency, but in the process of switch transform by changing the switch turn on time length, makes when load changes, and the output voltage of the load on the little change of method. But this kind of switch technology is a kind of "hard switch", namely the switch tube of on-off control and switch tube on the flow of electric current and has nothing to do with the voltage on both ends of the device, open and shut off the power switch tube is on the device of voltage or current force, under the condition of not equal to zero switching loss is very large. Especially in the modern power electronic technology is the direction of more high frequency to high frequency, hard switching PWM technology makes switch loss has become a significant obstacle of the development of high frequency is changed.

In the late 80s, pulse width modulation (SPWM) of soft switch technology, to promote the research and application of high power inverter technology level and on a new step. PWM soft switch technology combines the advantages of the traditional pulse width modulation technology and resonance technology, only in the instantaneous power semi-conduction device, the basis of the principle of resonance makes the switch of the converter switch device in the current (or voltage) by sine or quasi sine rule

\author{
Haijun Sun 2, b \\ 2 Gas Design Institute, \\ Shaanxi Xi'an,China \\ b E-mail: 45621157@qq.com \\ Chong Zhao 4, d \\ 4 Xijing University, \\ Shaanxi Xi'an,China \\ d E-mail: 36421157@qq.com
}

changes. When the current nature through the zero, it makes the device shut off; Or voltage is zero, the devices realizes zero switching loss, so as to realize zero voltage or zero current switching, and in most of the rest of the time with the method of constant frequency PWM, complete control of the power supply output voltage or current. So the current or voltage stress of switching devices is less. Under the guidance of this thinking, soft switch technology obtained the swift and violent development. In recent 10 years, constant frequency PWM soft switch technology in the power conversion circuit occupies a dominant position. Another DC-DC switching converter circuit topology structure, diversity and research progress of after making a combination of applied increasingly in the soft switch power converter. Soft switch technology research has become a current power electronics that is one of the most popular research directions.

Switching power supply includes input circuit, output power conversion circuit, output circuit, sampling circuit, control circuit, etc.Ac input voltage rectifier filter, through the input circuit to get a smooth dc high voltage; Dc high voltage by power conversion circuit transformation for the frequency is greater than $20 \mathrm{KHZ}$ high-frequency pulse voltage;High frequency pulse voltage by the output circuit is converted into a stable dc output voltage; Testing and sampling of the output voltage sampling circuit, eventually into modulation control circuit to control the power switch tube drive pulse width, so as to adjust the opening time to make the output voltage stability.

$\mathrm{AC}$ input voltage after input rectifier loop filtering into contains some volatility of dc power supply voltage, the voltage through the power transform circuit, the highfrequency transformer converts the voltage value of square wave, and then the square wave voltage by the output circuit of secondary rectifier filter into the required DC voltage and the output.Switch power supply, power adjustment device in the switch working state.Work in the state of the switch device, the turn-on of the pipe pressure drop is very small, can be used to approximate don't consume energy, its shut off when the leakage current is very small, and the approximate to not waste energy, so 
the power conversion efficiency of switch power supply is very high, usually can reach more than $85 \%$.

\section{THE DC SWITCHING POWER SUPPLY TOPOLOGY CLASSIFICATION}

Modern switching power supply is divided into two types of DC switching power supply and communication switching power supply, the output of high quality direct current, the output alternating current (AC) of high quality. In this paper, we study the DC converter, thus to introduce the classification of the dc converter.

DC converter according to whether there are electrical isolation between the input and output can be divided into two categories: no electrical isolation called isolated DC converter, electric isolation are called isolated DC converter. Not isolated DC converter according to the number of active power devices can be divided into three classes of single pipe, double pipe and four. Single tube dc converter has six kinds, namely the step-down converter (Buck), step-up (Boost) converter, lifting pressure type Buck/Boost converter, Cuk converter, Zeta converter and Sepic converter, etc. The six kinds of single tube decompression and booster in converter is the most basic, the other four are derived. Double tube dc converter has a double pipe string lifting pressure type Buck/Boost converter. The whole bridge dc converter (Full - bridge converter) is a common quads dc converter.

There are isolated dc converter can also be classified by the number of switching devices used. Single tube has Forward and Flyback type two kinds. Double tube has two pipe is Double transistor forward converter, Double transistor fly back converter, Push pull converter and Half - bridge converter. Four tube DC converter is Full bridge DC converter. DC with isolated converter usually uses transformer to realize electrical isolation between the input and output, and transformer itself has the function of the transformer, which helps to expand the application range of converter and easy to implement multiple different voltage or multiple of the same voltage output.

\section{FULL BRIDGE CONVERTER BASIC CIRCUIT AND WORKING PRINCIPLE}

In need of high power occasions, many DC/DC converter topologies, the full bridge converter is preferred. Because in the rated power switch tube voltage and current phase at the same time, the output power of the converter is proportional to the number of the switch tube used normally, so the output power of the full bridge converter is the largest. Full bridge converter consists of four power switch tube, the main transformer only need one original winding, direction is obtained by positive and reverse voltage magnetic flux, the best use of the transformer core and winding, improved efficiency and power density.

Full bridge converter with power switching device voltage and current rating is small, high efficiency of power transformer, so it obtaines wide application in practice. The transformation in the face of the whole bridge circuit in the working principle of PWM mode to do a brief description:

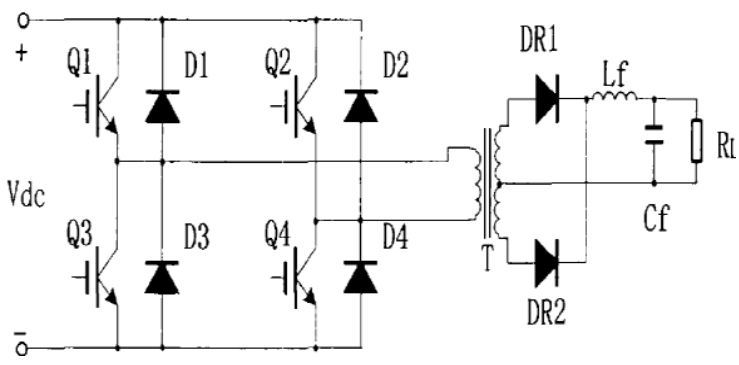

Figure 1. full bridge converter circuit structure

In the circuit shown in Fig .1. DC voltage Vdc applied in Q1, Q2, Q3 and Q4 four switch tubes of two bridge arms, and by controlling the on-off of the switch tube order on-off time, in the side of the transformer $\mathrm{T}$ change at a duty cycle $\mathrm{D}$ the positive and negative half cycle of symmetrical square wave AC voltage. If the transformer ratio of $\mathrm{N}$, the $\mathrm{AC}$ square wave voltage through the highfrequency transformer isolation and voltage change (stepup or step-down), after the deputy in the transformer corresponding get a Ui/N AC square wave voltage amplitude, ac square wave voltage Ul and through changing the output rectifier bridge for dc pulsed square wave voltage. At last, through the output filter inductor Lf DC square wave voltage and capacitance $\mathrm{Cf}$ the high frequency component of the filter, the outputs $\mathrm{Cf}$ gets a flat of DC voltage, the voltage $\mathrm{U} 0=\mathrm{Dui} / \mathrm{N}$, which is suitable for duty ratio $\mathrm{D}$. By adjusting the duty ratio can facilitate the adjustment of output voltage.

\section{THE FULL BRIDGE CONVERTER PWM CONTROL MODE}

Control method and circuit of dc converter topology, is also growing. Early full bridge converter control way for bipolar control mode, works in hard switching condition. Switch tube Q4 and Q1, Q2 and Q3 opens and shuts off at the same time, the two ways to switch tube to PWM alternating opens and shuts off, the opening time is not more than half of the switching cycle, their conduction angle is less than 180 degrees. When Q1 and Q4 conduction, Q2 and Q3 voltage for the Ui, and vice versa. When four switch tube is in off state, each switch tube under the voltage of the $\mathrm{Ui} / 2$. Junction capacitance by high-frequency transformer leakage inductance and switch in the switch process of high frequency oscillation is caused by the voltage spike, when its value is more than the input voltage, Dl-D4 clamping diodes will conduction, the switch at the ends of the tube voltage waveform muzzled on the input voltage. This kind of control mode, power transformation is through the interrupt power flow and the way to control the duty ratio, the working frequency is constant; Its working waveform is shown in Fig .2. Visible, Q1 and Q4 conduction, Q2 and Q3 conduction, at the same time, each tube conduction time is less than $1 / 2$ switching cycle. $\mathrm{Vl}$ is the original side voltage, high frequency transformer, and $\mathrm{VZ}$ is vice side of the high-frequency transformer voltage, and $\mathrm{Vr}$ is after rectification voltage, and DC voltage $\mathrm{Vo}_{\mathrm{O}}$ is after filtering. 

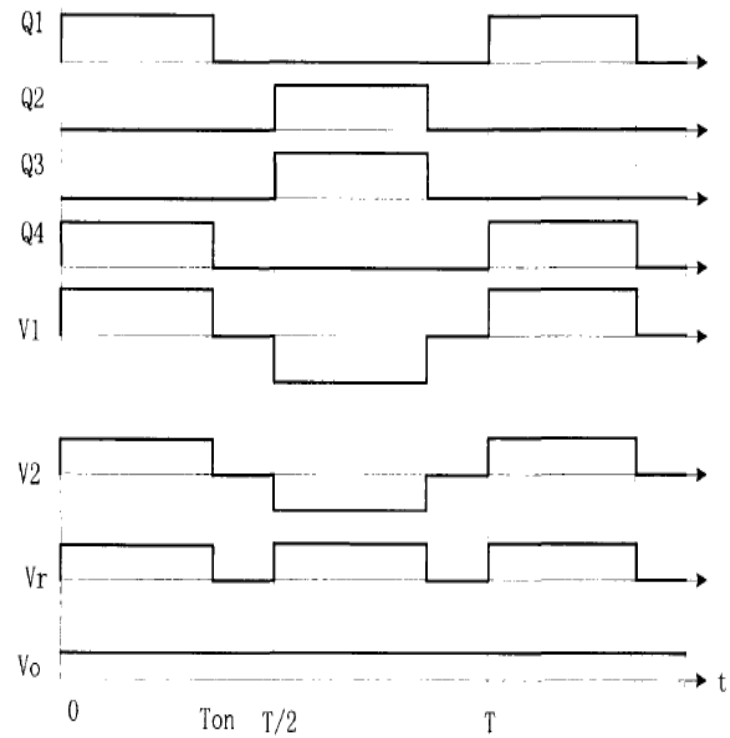

Figure 2. dual polarity control mode work waveform figure

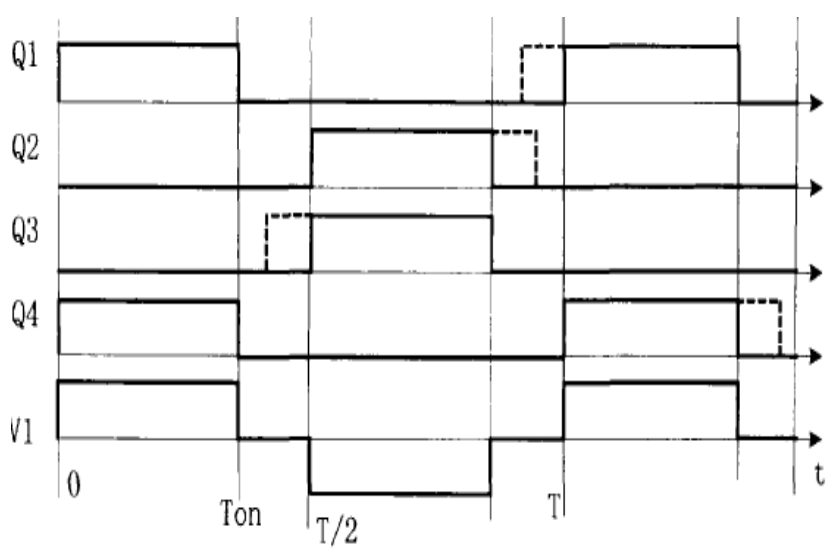

Figure 3. improved control waveform figure

The essence of the full bridge inverter PWM control is in the high frequency transformer primary side get a square wave ac voltage, thus produce a square wave ac voltage in high frequency transformer. Switch tube control method improvement, both limited bipolar control and phase shift control, are based on the following two points on the basis of.(1) The guarantee of high frequency transformer primary side of the AC voltage waveform is constant.(2) The switch tube of the same bridge arm, Q1 and Q3, Q2 and Q4 will not occur through phenomenon. So considered one of the switch tube opened ahead of time or the turn-off time delay, as long as the opening of the overlapping time constant, it can get the same voltage square wave. Improvement ways are: (1) Q2 and Q4 conduction time constant, Q1 and Q3 open ahead of time, and increase the conduction time ahead of time for a period of time or up to a half cycle;(2) Q1 and Q3 conduction time constant, Q2 and Q4 delay shut off, increase the conduction time back for a period of time or up to a half cycle;(3) Q1 and Q3 opened ahead of time, increase the conduction time forward for a period of time or up to half of the cycle, Q2 and Q4 delay shut off at the same time, increase the conduction time back for a period of time or up to half of the cycle. The improved control waveform is as shown in Fig.3.
So depending on the switch tube conduction time increased, the full bridge converter control strategy summary is divided into nine kinds of ways, they respectively. are:

(l) Q1 and Q3 conduction time constant, Q2 and Q4 conduction time is unchanged. This is the traditional dual polarity control mode;

Q2 and Q4 conduction time constant, Q1 and Q3 open ahead of time, increase the conduction time ahead of time for a period of time, increase after conduction time is less than $0.5 \mathrm{~T}$;

Q2 and Q4 conduction time constant, Q1 and Q3 open ahead of time, increase the conduction time ahead of time for a period of time, increase after conduction time is equal to $0.5 \mathrm{~T}$;

Q1 and Q3 conduction time constant, Q2 and Q4 delay shut off, increase the conduction time back for a period of time, increase after conduction time is less than $0.5 \mathrm{~T}$;

Q1 and Q3 conduction time constant, Q2 and Q4 delay shut off, increase the conduction time back for a period of time, increase the conduction time is equal to $0.5 \mathrm{~T}$ later, called limited bipolar control;

Q1 and Q3 opened ahead of time, increase the conduction time forward for a period of time, increase after conduction time is less than $0.5 \mathrm{~T} ; \mathrm{Q} 2$ and Q4 delay at the same time cut off, increase the conduction time after a period of time, increase after conduction time is less than $0.5 \mathrm{~T}$;

Q1 and Q3 opened ahead of time, increase the conduction time forward for a period of time, increase after conduction time is less than $0.5 \mathrm{~T}$; Q2 and Q4 delay at the same time cut off, increase the conduction time back for a period of time, increase after conduction time is equal to $0.5 \mathrm{~T}$;

Q1 and Q3 opened ahead of time, increase the conduction time forward for a period of time increase the conduction time is equal to grown since the end of the T; At the same time, the Q2 and Q4 delay shut off, increase the conduction time back for a period of time increase after conduction time is less than $0.5 \mathrm{~T}$;

Q1 and Q3 opened ahead of time, increase the conduction time ahead of time for a period of time, increase after conduction time is equal to $0.5 \mathrm{~T}$; Q2 and Q4 delay at the same time cut off, increase the conduction time back for a period of time, and increase the conduction time is equal to $0.5 \mathrm{~T}$ later, called phase shift control method.

More than nine kinds of control strategies includes the PWMDC/DC all full bridge converter control mode. According to the two diagonal switch tube shut off, it can be divided into two categories:

Two diagonal switch tubes shut off at the same time, the control mode $1 \sim 3$ belongs to this kind of control way.

Diagonally switch tubes stagger close time, a first off, after a turn off $4 \sim 9$ control way belongs to such a system way.

\section{CONCLUSIONS}

Switching power supply is a use of modern power electronic technology, power semiconductor devices as switch, control switch tube opening and closing time ratio, to ensure that the average output stable DC voltage power supply. It will power switch tube and energy storage 
element in some way connected, the switch tube open, inductance from the input voltage source for energy, and stored in the form of electromagnetic energy; In the switch tube shut off time, acquired by inductance releases energy to use and to provide an external circuit.Due to the switch power supply works in high frequency condition, and makes switch power supply device size dramatically, so the switching power supply is very suitable for portable electronic devices.

According to the different ways of connection and configuration of the power switch tube and energy storage devices switch power supply circuit can be divided into non segregation and isolation type two kinds of basic topology structure.Non isolation when it works in switching power supply is the feature of the input and output load current share a common pathway. Isolation is the input and output electrical, transmit energy by means of pulse transformer magnetic coupling.In the isolation transformer, according to the relationship of the input voltage and output voltage can be divided into type stepdown Buck converter, Boost type that the Boost converter, step-down or booster type Buck - Boost converter, its main application in DC/DC converter. In the isolated converter, according to the characteristics of the circuit can be divided into single-ended flyback type, single straight shock type, push-pull double side, half bridge type and bridge type.Switching power supply according to the different energy modulation mode can be divided into three types: pulse width modulation, pulse frequency modulation and pulse modulation.PWM modulation method can also be divided into voltage modulation mode and current modulation mode, the most widely used current modulation mode.

\section{REFERENCES}

[1] Heng Deng, Oruganti, R., Srinivasan, D., PWM methods to handle time delay in digital control of a UPS inverter. Power Electronics Letters, IEEE. Volume 3, Issue 1, March 2005 Page(s):1 - 6

[2] Buso, S., Fasolo, S., Mattavelli, P.. Uninterruptible power supply multiloop controlemploying digital predictive voltage and current regulators. Industry Applications, IEEE Transactions on. Volume 37, Issue 6, Nov.-Dec. 2001 Page(s):1846 - 185

[3] Amuda, L.N., Cardoso Filho, B.J., Silva, S.M., et al. Wide bandwidth single and three-phase PLL structures for grid-tied PV systems. IEEE-PSC, $2000: 1660$ - 1663

[4] Teodorescu, R, Blaabjerg, F..Flexible control of small wind turbines with grid failure detection operating in stand-alone and grid-connected mode. Power Electronics, IEEE Transactions on. Volume 19, Issue 5, Sept. 2004 Page(s):1323 - 1332

[5] Jovcic, D., Phase locked loop system for FACTS. Power Systems, IEEE Transactions on. Volume 18, Issue 3, Aug. 2003 Page(s): 1116 - 1124

[6] Fang Zheng Peng, Jih-Sheng Lai. Dynamic performance and control of a static VAr generator using cascade multilevel inverters. Industry Applications, IEEE Transactions on. Volume 33, Issue 3, May-June 1997 Page(s):748 - 755

[7] Rodriguez, P., Sainz, L., Bergas, J.. Synchronous double reference frame PLL applied to a unified power quality conditioner. HQP' $2002,(2): 614$ - 619

[8] Floyd M. Gardner. Phaselock Techniques. New York: Wiley, 1979

[9] Keliang Zhou, Yong Kang, Jian Chen, Study on the Mechanism of Waveform Distortion of PWM VSI with Rectifier Load , PESC' 98, 1998,Tokyo, Japan, pp.2083-2089

[10] Jong-Woo Choi, Seung-Ki Sul. Inverter output voltage synthesis using novel dead time compensation,Power Electronics, IEEE Transactions on, Volume 11, Issue 2, March 1996 Page(s):221 227. 